\title{
Targeting General Transcriptional Machinery as a Therapeutic Strategy for Adult T-Cell Leukemia
}

\author{
Regina Wan Ju Wong ${ }^{1}$, Takashi Ishida ${ }^{2}$ (D) and Takaomi Sanda ${ }^{1,3,4, * \text { (D) }}$ \\ 1 Cancer Science Institute of Singapore, National University of Singapore, Singapore 117599, Singapore; \\ csirwwj@nus.edu.sg \\ 2 Division of Hematology and Oncology, Department of Internal Medicine, School of Medicine, \\ Iwate Medical University, Morioka 020-8505, Iwate, Japan; itakashi@iwate-med.ac.jp \\ 3 Department of Medicine, Yong Loo Lin School of Medicine, National University of Singapore, \\ Singapore 117599, Singapore \\ 414 Medical Drive, Centre for Translational Medicine, \#12-01, Singapore 117599, Singapore \\ * Correspondence: takaomi_sanda@nus.edu.sg; Tel.: +65-6516-1016; Fax: +65-6873-9664
}

Received: 17 March 2018; Accepted: 28 April 2018; Published: 2 May 2018

\begin{abstract}
Cancer cells are highly reliant on certain molecular pathways, which support their survival and proliferation. The fundamental concept of molecularly targeted therapy is to target a protein that is specifically deregulated or overexpressed in cancer cells. However, drug resistance and tumor heterogeneity are major obstacles in the development of specific inhibitors. Additionally, many driver oncogenes exert their oncogenic property via abnormal expression without having genetic mutations. Interestingly, recent accumulating evidence has demonstrated that many critical cancer genes are driven by a unique class of enhancers termed super-enhancers. Genes associated with super-enhancers are relatively more susceptible to the inhibition of general transcriptional machinery compared with genes that are regulated by typical enhancers. Cancer cells are more sensitive to treatment with small-molecule inhibitors of CDK7 or BRD4 than non-transformed cells. These findings proposed a novel strategy to identify functionally important genes as well as novel therapeutic modalities in cancer. This approach would be particularly useful for genetically complicated cancers, such as adult T-cell leukemia (ATL), whereby a large mutational burden is present, but the functional consequences of each mutation have not been well-studied. In this review, we discuss recent findings on super-enhancers, underlying mechanisms, and the efficacy of small-molecule transcriptional inhibitors in ATL.
\end{abstract}

Keywords: super-enhancer; transcription factor; CDK7; CDK9; BRD4; adult T-cell leukemia

\section{Introduction}

Recent advancements in molecularly targeted therapy have yielded remarkable improvements in outcome for several cancers. Since the success of tyrosine kinase inhibitors such as imatinib and gefitinib in the early 2000s [1,2], a number of small-molecule inhibitors have been developed in the past two decades, many of which have been already tested in clinical trials $[3,4]$. This approach is supported by the concept that cancer cells are highly reliant on a certain driver oncogene; this phenomenon is termed oncogene addiction or pathway dependence [5-7]. Acute inhibition of the pathway that cancer cells depend on for their survival or proliferation results in a dramatic clinical response $[2,8]$. The application of whole genome and exome sequencing technologies has further provided a molecular understanding of the driver abnormalities in various cancers. However, we have also learned about several major challenges, including drug resistance and tumor heterogeneity. The emergence of resistant clones for biological or pharmacological reasons has occurred for almost all of the drugs 
that have been developed [9]. The genetic heterogeneity of mutational profiles among patients and the heterogeneity of cancer clones in the same patient or within the same tumor often impede the use of small-molecule inhibitors [10-12]. Several cancers associated with particular carcinogens typically exhibit a large number of genetic alterations [13]. Hence, the driver abnormalities could be different among patients. Therefore, in addition to pathohistological examination, further precise and prospective investigation of genetic abnormalities is necessary for the selection of therapeutic drugs [14,15]. Alternatively, it is important to identify and inhibit the molecular pathways that are commonly required for cancer cell survival and proliferation in different cases.

The most fundamental concept of molecularly targeted therapy is to target a protein that is specifically deregulated or overexpressed in cancer cells to avoid non-specific cytotoxicity in non-transformed cells. Thus, many of the small-molecule inhibitors that have been developed to date were designed to directly target an oncoprotein (disease gene). On the other hand, several new drugs that affect general cellular machinery have been recently developed and shown to possess potent anti-tumor cytotoxicity. These new drugs include small-molecule inhibitors of CDK7, CDK9, and BRD4, which block RNA polymerase II or histone activation, leading to transcriptional inhibition [16-18]. Although these inhibitors affect general transcriptional machinery, surprisingly, their effects were found to be relatively more specific to cancer cells than to non-transformed cells [16-18]. Treatment with these inhibitors results in the acute and concurrent downregulation of multiple oncogenes, thereby resulting in the disruption of various oncogenic mechanisms. Interestingly, recent genome-wide profiling of regulatory elements has shown that the genes that are sensitive to transcriptional inhibition are often regulated under a different class of enhancers called "super-enhancers", which exhibit a high level of active histone marks $[17,19,20]$. These findings suggested that the genes required for the maintenance of cancer cells need to be continuously expressed at a high level to sustain their survival and proliferation.

\section{Deregulation of Enhancers in Cancers}

Enhancers are regulatory elements that are bound by transcription factors and activate transcription through interactions with promoter elements [21-24] (Figure 1A). Combinations of the various histone marks that are associated with specific chromatin and transcriptional status have been used to characterize putative enhancer and promoter regions [22,23] (Figure 1B). The application of recent chromatin immunoprecipitation-sequencing (ChIP-seq) technology and chromosome conformation capture assays allowed us to predict regulatory elements on a genome-wide scale in various cell types. Importantly, enhancers are dynamic, changing their activity and landscape during developmental processes or upon environmental changes, and allowing cells to produce a complex pattern of gene expression. As such, the strict and tight regulation of enhancers is necessary for tissue homeostasis. In other words, aberrant functioning of enhancers leads to pathogenesis such as cancer.

The abnormal activation or repression of enhancers is often found in cancer cells, and is closely associated with the misexpression of cancer genes [21,24]. A classic example is the chromosomal translocation involving the T-cell receptor (TCR) or immunoglobulin (Ig) gene locus in lymphoid malignancies, which replaces the regulatory element of a translocation partner gene and drives its expression [25]. Many proto-oncogenes, such as MYC, BCL2, and TAL1, were identified from the breakpoints of chromosomal translocation in leukemias and lymphomas [25]. In these cases, the affected proteins are structurally intact, and thus, the overexpression or ectopic expression of wild-type genes can drive carcinogenesis. This is in contrast to many kinase abnormalities, which are often functionally altered due to genetic mutations. In addition to chromosomal translocation, several other mechanisms that activate enhancers have been reported. As a recent example, Mansour et al. identified small nucleotide insertions in non-coding elements upstream of the TAL1 oncogene in a subset of T-cell acute lymphoblastic leukemia (T-ALL) cases [26]. This insertion creates a binding motif that can be recognized by the MYB transcription factor, leading to the generation 
of a new and powerful enhancer driving TAL1 expression. Similarly, mutations or single nucleotide polymorphisms (SNPs) in regulatory elements at the LMO1 or LMO2 gene locus have been reported in neuroblastoma and T-ALL cases [27-29]. Mutations in the TERT gene promoter that enhance its expression have been found in several cancers [30-32]. These findings indicate that the aberrant activation of regulatory elements can be a primary driver mechanism for carcinogenesis. Conversely, the regulatory elements of tumor suppressor genes are frequently silenced due to DNA methylation and/or histone modification in various types of cancers [33,34]. Misexpressions or genetic mutations of chromatin modifiers and epigenetic regulators such as EZH2, DNMT3A, MLL, and ARID1A are often found in hematological malignancies and solid tumors, leading to global alterations of the gene expression program [34,35]. Therefore, it is crucial to identify the regulatory elements of genes for a molecular understanding of cancer.

A

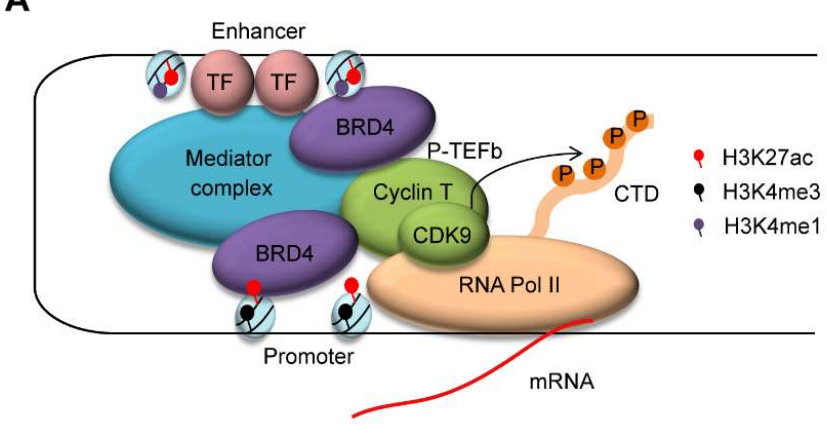

B

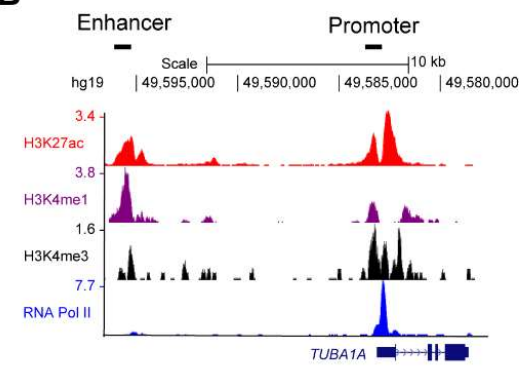

Figure 1. (A) Enhancers are bound by transcription factors (TFs). The mediator complex aids in chromatin-chromatin interaction between enhancer and promoter regions. Enhancer and promoter regions are primarily enriched for $\mathrm{H} 3 \mathrm{~K} 27 \mathrm{ac} / \mathrm{H} 3 \mathrm{~K} 4 \mathrm{me} 1$ and $\mathrm{H} 3 \mathrm{~K} 27 \mathrm{ac} / \mathrm{H} 3 \mathrm{~K} 4 \mathrm{me}$, respectively. BRD4 binds to the acetylated lysine residue of histone $\mathrm{H} 3$ and recruits the P-TEFb complex (CDK9/Cyclin T), which in turn phosphorylates the C-terminal domain (CTD) of RNA Polymerase II (Pol II) at serine 2 residue. (B) An example of chromatin immunoprecipitation-sequencing (ChIP-seq) analysis for histone modifications (H3K27ac, H3K4me1, and H3K4me3) and RNA Pol II in a T-cell acute lymphoblastic leukemia (T-ALL) cell line (Jurkat). The datasets have been reported in Mansour et al. [26], Sanda et al. [36] and Leong et al. [37]. The y-axis represents the total number of mapped reads per million at the TUBA1A gene locus. A putative enhancer region enriched for $\mathrm{H} 3 \mathrm{~K} 27 \mathrm{ac} / \mathrm{H} 3 \mathrm{~K} 4 \mathrm{me} 1$ and a promoter region enriched for H3K27ac/H3K4me3 are indicated.

\section{Super-Enhancers in Normal Development and Cancers}

Given the importance of regulatory elements in normal development and pathogenesis, a current area of major research interest is the identification of regulatory elements using genome-wide technologies, such as ChIP-seq [38]. This led to the discovery of a different class of enhancers $[17,19,20]$. Typically, an enhancer shows a single peak or a few peaks, such as for example by ChIP-seq analysis for H3K27ac (Figure 2A, bottom left). In contrast, there are clusters of enhancers that show significantly high levels of histone marks (Figure 2A, bottom right). Richard Young et al. first described those elements and proposed the new term "super-enhancer" $[17,19,20]$. Super-enhancers are defined by bioinformatics analysis through ranking all of the putative enhancer elements that are based on ChIP-seq signals, typically for H3K27ac (Figure 2B). However, similar trends can also be observed by ChIP-seq analysis for other enhancer marks (H3K4me1) and mediator proteins or by other methods, including DNase I hypersensitivity assays and Assay for Transposase-Accessible Chromatin using sequencing (ATAC-seq) analysis [20,39]. Although the super-enhancer concept was originally proposed based on bioinformatics analysis, the biological significances of this concept are now being recognized.

In early studies by the Young laboratory, super-enhancers were analyzed in mouse embryonic stem cells (mESCs) and various differentiated cells. They were shown to be associated with critical genes involved in regulating cell fate and identification during normal development [19]. 
For example, genes encoding pluripotency transcription factors-namely, Oct4, Sox2 and Nanog-were associated with super-enhancers in mESCs [19]. In differentiated muscle cells, genes coding the master transcription factor $M y o D$ were regulated by super-enhancers [20]. Likewise, the T-cell transcription factor T-bet was driven by super-enhancers specifically activated in T-cells [20]. Similar findings were observed in various types of cells. Interestingly, super-enhancers were also enriched at critical cancer genes, including oncogenes and tumor suppressors. In the catalog of super-enhancers in the 86 cancer cell lines reported by Hnisz et al., super-enhancers were found to be associated with many known oncogenes [19]. In T-ALL cell lines, a large super-enhancer was found at the TAL1 enhancer locus that was generated by a mutation [18,26] (Figure 2A, bottom right). Super-enhancers were also found at the GATA3, RUNX1, and MYB genes, which are involved in the TAL1-induced core regulatory circuit [36], as well as at the CDK6 oncogene. The association of super-enhancers with oncogenes is also evident in many other cancers. For example, super-enhancer-associated genes include IRF4 and MYC in multiple myeloma [40], PAX5, MYC, and IRF4 in diffuse large B-cell lymphoma [41], MYCN and ALK in neuroblastoma [42], and CDK6, MYC, and EGFR in glioblastoma [17,20]. These studies suggested that cancer cells may require super-enhancers at key oncogenes to maintain their high level of expression, and allow cancer hallmark traits to be acquired during tumorigenesis. Therefore, the inhibition of super-enhancer activities may serve as a potential therapeutic strategy in various malignancies.

A

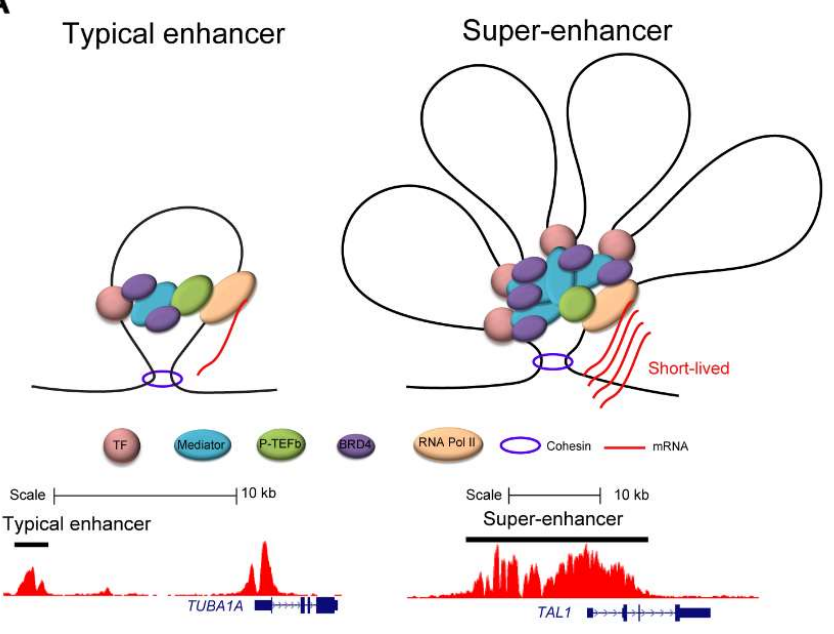

B

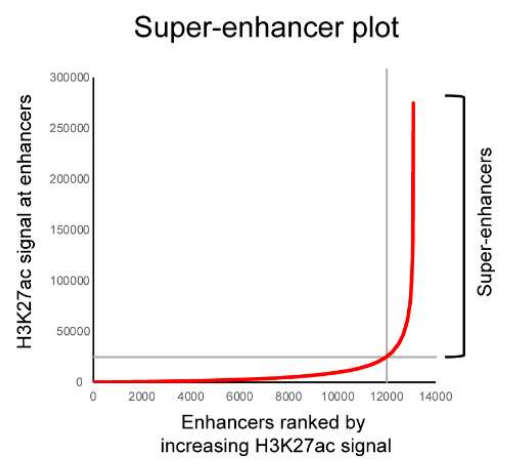

Figure 2. (A) Schematic images (top) and examples (bottom) of typical enhancers and super-enhancers. ChIP-seq gene tracks for H3K27ac at TUBA1A and TAL1 gene loci in Jurkat cells are shown. The datasets have been reported in Mansour et al. [26], Sanda et al. [36] and Leong et al. [37]. Black bars represent the putative enhancer elements at each locus. (B) A super-enhancer plot showing an example of super-enhancer analysis in an adult T-cell leukemia (ATL) cell line (TL-Om1) analyzed by the ROSE program $[17,19,20]$. The dataset has been reported in Wong et al. [43]. Briefly, all of the putative enhancer elements are identified by ChIP-seq analysis for H3K27ac. Constituent enhancers are stitched together and then plotted in rank order of increasing H3K27ac signals. Super-enhancers are defined to be those at the right of the inflection point of the curve.

\section{Targeting General Transcriptional Machinery as a Novel Therapeutic Approach}

The strategy of targeting enhancers is ideal for several cancers in which proto-oncogenes are driven by enhancer abnormalities. One approach is to block the binding of responsible transcription factors. However, the "druggability" of transcription factors has been a big challenge since the inception of molecularly targeted therapy. Transcription factors are generally difficult to directly target with small-molecule inhibitors due to insufficient structural information regarding their interaction profiles with one another and their binding modes to DNA [44,45]. Additionally, transcription factors often work together as a complex or work with regulatory partners. As such, the inhibition of a single 
transcription factor may not be sufficient to modulate transcriptional activity. Therefore, it would be more ideal to target the general transcriptional machinery. However, this suggestion raises a fundamental question. Can the inhibition of general machinery yield a selective block of target genes or specificity of target cells? Recent studies using small-molecule inhibitors of BRD4 and CDK7 have provided several important insights in relation to this question.

The first breakthrough was made by James Bradner et al. in the early 2010s using JQ1, a small-molecule inhibitor of BRD4 [46]. BRD4 belongs to the BET (bromodomain and extra-terminal) family of proteins, and is required to recruit transcriptional elongation factor $\mathrm{P}-\mathrm{TEFb}$ to acetylated chromatin, which results in the displacement of negative regulators, such as HEXIMI and 7SKsnRNA, from P-TEFb [47] (Figure 1A). The inhibition of BRD4 essentially blocks transcriptional elongation (Figure 3, right). JQ1 has been shown to selectively bind to the amino-terminal twin bromodomains of BRD4 to impair its ability to bind to acetylated histones [46]. Several other BET bromodomain inhibitors, such as I-BET, have also been developed and tested in cancers [48,49]. Importantly, the treatment of these inhibitors causes a remarkable inhibition of the expression of MYC and many of the oncogenes that are associated with super-enhancers in various cancers [17,50-52]. BRD4 inhibitors preferentially suppress the transcription of cancer-promoting genes compared with housekeeping genes, thereby resulting in the potent cytotoxicity in cancer cells [17,41]. Thus, studies with BRD4 inhibitors indicated that the inhibition of general transcriptional machinery could be a therapeutic option for cancer.

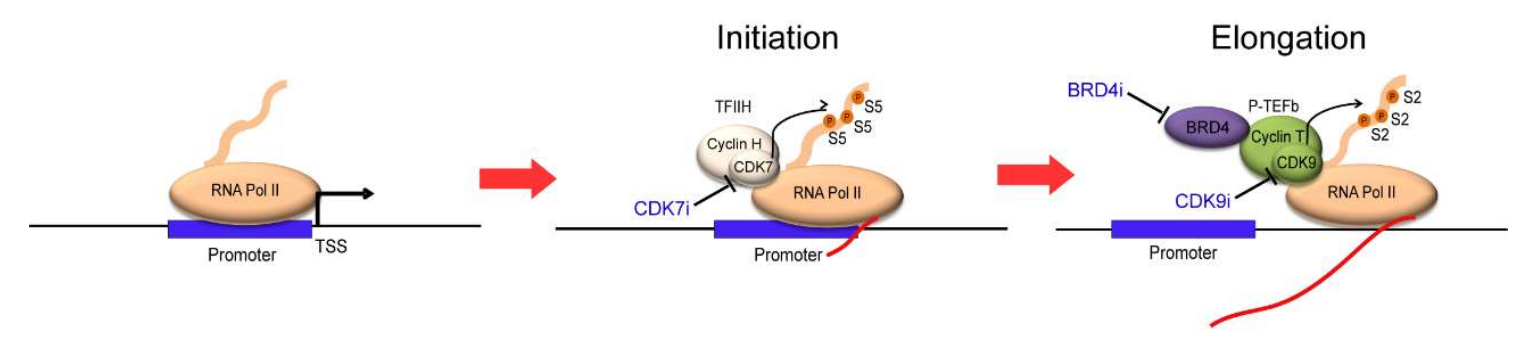

Figure 3. The CTD of RNA Pol II is first phosphorylated by the TFIIH complex (CDK7/Cyclin H) at serine 5 residue to initiate transcription. The P-TEFb complex (CDK9/Cyclin T) further phosphorylates RNA Pol II at serine 2 residue to facilitate transcriptional elongation. Small-molecule inhibitors of BRD4 (BRD4i), CDK7 (CDK7i), and CDK9 (CDK9i) block each of these processes.

This idea was further supported by the development of CDK7 inhibitors. CDK7 is a kinase that phosphorylates the C-terminal domain (CTD) of RNA polymerase II at the serine 5 residue, which is required for the initiation of transcription [53] (Figure 3, middle). The inhibition of CDK7 results in the inactivation of RNA polymerase II, leading to a transcriptional block. This effect can be achieved, for example, by using a small-molecule CDK7 inhibitor, THZ1, which was developed by Nathanael Gray et al. [18]. THZ1 covalently binds to the CDK7 protein and irreversibly inhibits its kinase activity, resulting in the reduction of RNA polymerase II CTD phosphorylation. Interestingly, through the screening of over 1000 cell lines, many cancer cell lines were found to be sensitive to THZ1 treatment. As an example, they described that T-ALL cells were very sensitive to CDK7 inhibition; the cell growth of T-ALL cell lines was inhibited at $\mathrm{IC}_{50}$ values under $100 \mathrm{nM}$ [18]. T-ALL cells underwent apoptosis in response to low doses of THZ1 treatment, whereas cell cycle arrest was observed in non-transformed BJ fibroblasts and RPE-1 cells at higher doses. This result suggested that normal cells might be less reliant on genes that are sensitive to transcriptional inhibition. Notably, compared with typical enhancer-associated genes, super-enhancer-associated genes, such as TAL1, GATA3, RUNX1, and $M Y B$ and the oncogene BCL2, were more strongly downregulated in T-ALL cells after treatment with THZ1 [18]. In contrast, housekeeping genes, such as TUBA1A (encoding $\alpha$-tubulin), were not associated with super-enhancers (Figure 2A, left), and their expression was hardly affected by THZ1 treatment, even though they were highly expressed. Similar results have been reported in other 
cancers, including neuroblastoma, small cell lung cancer, and nasopharyngeal carcinoma [42,54,55]. These studies suggested that cancer cells are more sensitive to transcriptional inhibition, and that super-enhancer-associated genes are more preferentially affected after inhibition than typical-enhancer associated genes.

\section{Possible Mechanisms That Determine Sensitivity to Transcriptional Inhibitors}

The aforementioned studies on BRD4 and CDK7 inhibitors highlighted the feasibility of inhibiting the general transcriptional machinery as a therapeutic approach against cancer. However, this result has also raised additional questions. Why are super-enhancer-associated genes more sensitive to these inhibitors than other genes? Is the super-enhancer functionally different from typical enhancers?

Fundamentally, super-enhancers are defined by bioinformatics analysis (Figure 2B). Super-enhancers could be simply the sum of their constituent enhancers, and may not be biologically distinct from typical enhancers. This has been a major debate since this concept was proposed. One plausible explanation is that super-enhancers possess a different chromatin structure and a high density of transcriptional regulators compared with typical enhancers (Figure 2A). In this regard, a phase separation model was proposed to explain the preferential sensitivity of super-enhancers to the inhibition of general transcriptional machinery [56]. Many of the transcriptional components that are present in enhancers can be modified at multiple sites, for example, the phosphorylation or dephosphorylation of the CTD of RNA polymerase II and acetylation or methylation of histones and other transcriptional regulators. Consequently, these chemical modifications allow the components to physically interact with each other, forming "crosslinks". The formation of such "crosslinks" is therefore dependent on the strength of the chemical interactions between the chemically modified sites. Considering this point, the density of transcriptional components within super-enhancers is remarkably high, possibly allowing the formation of densely connected biomolecular structures that are termed "condensates" through these chemical interactions [57]. Hence, the inhibition of BRD4 or CDK7 would be particularly detrimental to the establishment or maintenance of super-enhancers because of their high "valency", which is a parameter corresponding to the number of modifiable residues that can affect the engagement of a crosslink. This model implicated the critical roles of BRD4 and CDK7 for the stability of "crosslinks" at super-enhancers.

Another possible explanation is that super-enhancer-associated genes may have different kinetics in transcription. These transcripts could be relatively short-lived, and thus, transcription needs to be continuously activated to maintain their expression. It has been shown that the inhibition of CDK9, which facilitates transcription elongation, primarily affects the accumulation of transcripts with short half-lives, including genes encoding for anti-apoptosis family members and cell cycle regulators [58,59]. Similarly, the inhibition of CDK7 primarily affected mRNA with high turnover rates [60]. Thus, the newly transcribed RNAs (nascent RNAs) are highly dependent on CDK7 and CDK9 and its associated mechanisms, which may require super-enhancers to be continuously transcribed, in order to support cell survival and proliferation. Hence, the inhibition of transcriptional machinery in cancer cells could result in the preferential inhibition of genes that are required for their maintenance.

\section{Application of Super-Enhancer Profiling and Transcriptional Inhibition to Genetically Complicated Cancer}

The development of transcriptional inhibitors provided a new option for cancer therapeutics. Additionally, determination of the susceptibility to transcriptional inhibition can be a novel strategy to identify the critical genes that are required for the maintenance of cancer cells. Early studies on super-enhancers and transcriptional inhibitors were done in T-ALL and neuroblastoma [18,42], which possess a relatively smaller number of genetic and chromosomal abnormalities than other hematological malignancies and solid tumors [13]. One intriguing question is whether the same strategy can be extrapolated to more complicated cancers in which a larger number of abnormalities and greater genetic heterogeneity are prevalent. To test this idea, we recently performed super-enhancer 
profiling in one of the most intractable cancers, adult T-cell leukemia (ATL), and tested the therapeutic efficacy of CDK7 inhibitors in this disease.

\section{Molecular Pathogenesis of ATL}

ATL is a hematological malignancy derived from T-cells [61-63]. There are many marked contrasts between T-ALL and ATL. T-ALL arises from immature thymic T-cell precursors, and is classified under acute leukemia in the World Health Organization (WHO) classification, whereas ATL arises from CD4-positive mature T-lymphocytes, and is classified under mature T and NK neoplasms [64,65]. T-ALL primarily affects young children, whereas ATL mostly occurs in adults of over 50 years old, which is the major limiting factor for the application of high-dose chemotherapy. Additionally, ATL cells are often resistant to conventional chemotherapeutic agents. These characteristics contribute to the dismal prognosis of ATL with the four-year survival rate for the acute-type being less than $20 \%[66]$.

Importantly, the transformation process of ATL is highly complicated, and involves multiple mechanisms. The development of ATL is closely associated with the infection of human T-lymphotropic virus type-I (HTLV-1), which is endemic in certain parts of the world, including the southern part of Japan, the Caribbean, and South American and African countries [61]. The viral protein Tax promotes the proliferation of HTLV-I-infected T-cells; however, this gene is often silenced at the diagnosis of ATL, which likely enables the infected cells to escape from host-immune defense [67]. Another important viral gene is $H B Z$, which is continuously expressed throughout the course of the disease and is required for the maintenance of ATL cells and the immunophenotype of HTLV-1-infected cells [68]. Notably, ATL typically arises after 30-50 years of viral infection, and only less than $5 \%$ of carriers develop this disease [61-63]. Epidemiological studies suggested that the accumulation of multiple genetic and epigenetic abnormalities throughout the latency period would be essential for the complete transformation of infected T-cells [69].

The significance of genetic abnormalities was further elucidated by a recent study using whole genome and exome sequencing technology [70]. Kataoka and Ogawa et al. analyzed mutational profiles in an impressive cohort of 426 ATL samples. Using whole genome sequencing and SNP array-based copy number analysis, they identified approximately 60 structural variations per sample on average, and identified a large number of genetic and chromosomal abnormalities, including activating mutations of PLCG1 (36\%), PRKCB (33\%), CARD11 (24\%), VAV1 (18\%), IRF4 (14\%), and CCR7 (11\%) in their cohort. They found that many of the mutated genes, such as PLCG1, PRKCB, CARD11, and STAT3, are involved in the T-cell receptor (TCR)-NF- $\mathrm{BB}$ signaling, T-cell trafficking, and immunosurveillance pathways. The accumulation of additional mutations in genes involved in the TCR-NF-kB pathways, along with the inactivation of TP53 and CDKN2A and other mutations, is likely required for the transformation of T-cells into fully malignant cells.

In addition to genetic abnormalities, several groups have reported the involvement of epigenetic abnormalities in ATL pathogenesis [63]. The EZH2 gene, which encodes a component of the Polycomb repressive complex 2 (PRC2), was found to be significantly highly expressed and accompanied with enhanced H3K27me3 repressive chromatin marks in ATL cells compared to its normal CD4+ counterparts [71]. Integrative analyses of the epigenome of primary ATL cells by Fujikawa and Watanabe et al. revealed that a global gain of H3K27me3 facilitated by PRC2-mediated epigenetic reprogramming is prevalent in ATL [72].

All of these findings indicate that multiple oncogenic mechanisms are involved in ATL. Given the high mutational prevalence of ATL cells, it is difficult to determine the functional property of each mutated gene. Since ATL also exhibits high heterogeneity among patients, it is more reasonable to identify and target molecular pathways that are commonly deregulated across different ATL cases and are functionally important for pathogenesis. Therefore, it would be feasible to apply super-enhancer profiling to identify critical cancer genes and test transcriptional inhibitors in ATL. 


\section{Super-Enhancer Profiles in ATL}

In our latest study by Wong and Ngoc et al. [43], we performed super-enhancer profiling for 10 primary ATL samples (nine acute type and one chronic type), and one ATL cell line (TL-Om1) by ChIP-seq analysis for H3K27ac. From this analysis, we identified hundreds of super-enhancers in each sample. We then selected 376 super-enhancer-associated genes that were commonly present in more than five of 10 primary samples. For example, IL2RA/CD25, CD28, TNFRSF8/CD30, FYN, and NFATC1/2 were identified in our study. Interestingly, many of these genes were enriched in the TCR pathway, substantiating the finding by Kataoka et al., which reported that the TCR pathway was often affected by genetic mutations in ATL cells [70].

We then compared this result with profiles in normal T-cells (thymus, Th1, Th2, and Th17) and T-ALL cells. Importantly, three distinct sets of genes surfaced from this analysis. The first set consisted of genes that were commonly associated with super-enhancers in ATL cells, normal T-cells, and T-ALL cells. This set included $C D 2$, which has been recognized as a T-cell marker. The second consisted of genes that were associated with super-enhancers in ATL and normal mature T-cells (Th1, Th2, and Th17) but not in normal thymus or T-ALL cells, including the CD25/IL2RA gene. This result supported previous findings that ATL arises from CD4+CD25+ mature T-cells [73,74]. Lastly, we found genes that were associated with super-enhancers specifically in ATL samples, but not in normal T-cells. An example was TP73, which is a member of the p53 tumor suppressor family. This gene is normally induced upon intracellular stress, such as DNA damage [75-77], and is often activated in certain types of solid tumors that exhibit genomic instability [77]. Thus, formation of the TP73 super-enhancer may reflect the intracellular status of ATL cells. Taken together, our results supported previous findings in other cell types that super-enhancers are enriched in genes that characterize cell identity and fate.

\section{Application of the Small-Molecule CDK7 Inhibitor}

In the same study, we also tested the efficacy of targeting CDK7 kinase in ATL cells [43]. Several ATL cell lines and primary samples were very sensitive to the pharmacological inhibition of CDK7 using small-molecule inhibitor THZ1, even at $\mathrm{IC}_{50}$ values below $50 \mathrm{nM}$. THZ1 treatment efficiently blocked the phosphorylation of RNA polymerase II in sensitive ATL cell lines with a concomitant induction of apoptosis. This study highlighted the feasibility of CDK7 inhibition as a therapeutic option in ATL. Hence, we also performed the gene expression profiling after CDK7 inhibition to find genes that were susceptible to the transcriptional inhibition in ATL cells. We combined this result with super-enhancer profiling to identify potential cancer genes.

Importantly, we have identified the CCR4 gene to be regulated under super-enhancers in all of the examined ATL samples, but not in normal T-cells or T-ALL cells. The CCR4 protein has been known to be highly expressed in the majority of ATL cases [78-81]. The expression of CCR4 was significantly downregulated upon THZ1 treatment, further indicating the involvement of this gene in the pathogenesis of ATL. Additionally, from this analysis, we identified a previously uncharacterized gene, TIAM2. This gene was also associated with super-enhancers in all of the examined ATL cases, but not in normal T-cells. The genetic knockdown of TIAM2 inhibited cell growth and induced apoptosis in ATL cells, whereas the overexpression of TIAM2 in T-ALL cells promoted cell growth. This result implicated TIAM2 as a novel candidate cancer gene in ATL. Thus, our approach has successfully demonstrated the potential application of super-enhancer profiling to identify critical cancer genes in genetically complicated cancers.

\section{Therapeutic Efficacy of the Small-Molecule CDK9 Inhibitor}

The use of small-molecule inhibitors of CDK9 has also been explored in ATL and HTLV-1-infected T-cells. The kinase CDK9 is the catalytic subunit of the P-TEFb complex, which activates RNA polymerase II by phosphorylating the serine 2 residue in CTD to facilitate transcription elongation [53] (Figure 3, right). The optimization of a lead compound, BAY 958, which was based on kinase selectivity, 
physicochemical and drug metabolism, and pharmacokinetics properties, led to the identification of an orally available small-molecule CDK9 inhibitor, BAY 1143572 (atuveciclib; Bayer AG Pharmaceuticals Division, Berlin, Germany) [82]. Currently, this inhibitor is being tested in phase I clinical trials for advanced solid tumors and acute leukemia [83].

Recently, Narita and Ishida et al. investigated the therapeutic efficacy of this CDK9 inhibitor on ATL [84]. BAY 1143572 effectively inhibited CDK9, leading to a reduction in phosphorylation at serine 2 of RNA polymerase II in ATL-derived cell lines and HTLV-1-transformed T-cell lines, as well as in primary ATL samples. Growth inhibition and apoptosis induction were observed and associated with decreased MYC and MCL1 expressions. The administration of BAY 1143572 in immunocompromized NOD/Shi-scid/IL-2R $\gamma^{\text {null }}$ (NOG) mice xenografted with patient-derived ATL cells greatly reduced the infiltration of ATL cells into organs, such as liver and bone marrow. Decreased human soluble IL2R levels in serum were also observed, which indicated a reduction of ATL tumor burden. This study revealed the importance of CDK9-mediated transcription in ATL pathogenesis and implicated CDK9 inhibitors as a novel therapeutic agent for ATL.

\section{Therapeutic Efficacy of the Small-Molecule BRD4 Inhibitor}

The small-molecule inhibitor of BRD4 has also been tested in HTLV-1-infected cells. It is noteworthy that the inhibition of BRD4 can exert an additional anti-cancer mechanism besides the inhibition of general transcriptional machinery in ATL or HTLV-1-infected cells. It has been reported that BRD4 mediates the activation of NF-KB. Acetylation of the p65 subunit of NF- $\mathrm{KB}$ at lysine 310 and the subsequent recruitment of BRD4 have been shown to be essential for the activation of NF- $\mathrm{B} B$ in response to various stimuli [85]. Upon the binding of BRD4 to acetylated p65, CDK9 is recruited to phosphorylate and activate RNA polymerase II for the transactivation of NF- $\kappa B$ target genes. Importantly, NF- $\mathrm{KB}$ is often constitutively activated in ATL cells in HTLV-1-dependent and independent manners $[86,87]$. The viral oncoprotein Tax can activate the NF- $\mathrm{KB}$ pathway through the interactions with TAK1 and NEMO/IKK $\gamma[88,89]$. Kataoka and Ogawa et al. reported that many of the genes that frequently mutated in ATL are enriched in the T-cell receptor-NF- $\mathrm{KB}$ pathway [70]. Our study with super-enhancer profiling also supported this finding [43]. NF- $\mathrm{KB}$ can activate cell survival in ATL cells by regulating genes such as BCL2, BCL-xl, and IAP family proteins, for example [90,91]. Therefore, targeting NF- $\mathrm{KB}$ provides an ideal therapeutic strategy.

Interestingly, treatment with the BRD4 inhibitor JQ1 has been shown to inhibit proliferation and induce apoptosis in Tax-expressing rat fibroblasts and Tax-positive HTLV-1 infected cells [92]. JQ1 treatment triggered polyubiquitination and the subsequent proteasome-mediated degradation of constitutively active nuclear NF- $\mathrm{kB}$, resulting in the selective inhibition of the expression of NF- $\mathrm{KB}$ target genes. JQ1 treatment also resulted in the decreased expression of IL2RA and inhibited the growth of HTLV-1 infected cells. Of note, JQ1 also inhibits the proliferation of some Tax-negative HTLV-1 infected cells [92]. This finding indicated the broad application of BET inhibitors in the early stage of HTLV-1 infection, as well as for the treatment of ATL.

\section{Conclusions and Future Perspectives}

Recent mutational profiling by whole genome and exome sequencing has provided a large catalog of mutations in protein-coding genes. However, drug resistance and tumor heterogeneity are major obstacles in the development of specific inhibitors. Additionally, many driver oncogenes exert their oncogenic property via abnormal expression due to enhancer abnormalities, and do not have mutations within protein-coding elements. Therefore, it is critical to determine the driver abnormality that directly contributes to tumorigenesis. This is particularly evident for genetically complicated cancers, such as ATL, whereby a large mutational burden is present, but the functional importance of each mutation has not been well-studied.

In this review, we discussed the therapeutic efficacy of transcriptional inhibitors as well as potential applications of super-enhancer profiling to identify cancer genes. Recent studies suggested 
that super-enhancers would be required to maintain the expression of critical cancer genes. This would be a common and fundamental mechanism to support cancer cell survival and proliferation, although the acting oncogenes could be different among various cancer types. Given the biological importance of super-enhancers in cancers, super-enhancers represent feasible therapeutic targets. The blocking of super-enhancer-driven transcription resulted in the acute and concurrent disruption of multiple oncogenic machineries to which cancer cells are addicted, regardless of their mutational profiles. Thus, the use of small-molecule inhibitors targeting transcriptional regulators, such as CDK7, CDK9, and BRD4, is an ideal approach. However, we are not optimistic, as no single inhibitor is likely to achieve a maximal anti-cancer effect. A combination treatment with existing therapies is required. Moreover, drug resistance towards THZ1 has already been reported in some cases of MYCN-driven neuroblastoma cells in which prolonged treatment with THZ1 resulted in an upregulation of the drug transporters responsible for extruding a variety of drugs [93]. Resistance to JQ1 due to the hyperphosphorylation of BRD4 has also been reported [94]. Hence, a challenge for transforming the use of these inhibitors from lab bench to clinical use will be to improve the specificity of these drugs and overcome the resistance to these agents.

Acknowledgments: We thank Phuong Cao Thi Ngoc for processing the ChIP-seq dataset in our previous study, and Stella Amanda and Wei Zhong Leong for their discussions and critical reviews. This research is supported by the National Research Foundation (NRF), Prime Minister's Office, Singapore, under its Competitive Research Programme (NRF-NRFF2013-02), and also supported by the NRF and the Singapore Ministry of Education under its Research Centres of Excellence initiative. This work is also supported by grants-in-aid for scientific research (B) (16H04713 to T.I.), and grants-in-aid from the Japan Agency for Medical Research and Development (17ck0106287h0001, 16cm0106301h0001, and 15ck0106132h0002 to T.I.). We acknowledge support by the Yong Loo Lin School of Medicine BSL-3 Core Facility, National University of Singapore, National University Health System and the Singapore Ministry of Health, National Medical Research Council, Center Grant 'MINE', Research Core \#4 (NMRC/CG/013/2013).

Conflicts of Interest: R.W.J.W. and T.S. have no conflict of interest to disclose. T.I. obtained research funding from Kyowa Hakko Kirin Co., Ltd., Bayer AG, and Celgene K.K., and honoraria from Kyowa Hakko Kirin Co., Ltd., and Celgene K.K.

\section{References}

1. Druker, B.J.; Talpaz, M.; Resta, D.J.; Peng, B.; Buchdunger, E.; Ford, J.M.; Lydon, N.B.; Kantarjian, H.; Capdeville, R.; Ohno-Jones, S.; et al. Efficacy and safety of a specific inhibitor of the BCR-ABL tyrosine kinase in chronic myeloid leukemia. N. Engl. J. Med. 2001, 344, 1031-1037. [CrossRef] [PubMed]

2. Lynch, T.J.; Bell, D.W.; Sordella, R.; Gurubhagavatula, S.; Okimoto, R.A.; Brannigan, B.W.; Harris, P.L.; Haserlat, S.M.; Supko, J.G.; Haluska, F.G.; et al. Activating Mutations in the Epidermal Growth Factor Receptor Underlying Responsiveness of Non-Small-Cell Lung Cancer to Gefitinib. N. Engl. J. Med. 2004, 350, 2129-2139. [CrossRef] [PubMed]

3. Zhang, J.; Yang, P.L.; Gray, N.S. Targeting cancer with small molecule kinase inhibitors. Nat. Rev. Cancer 2009, 9, 28-39. [CrossRef] [PubMed]

4. Gharwan, H.; Groninger, H. Kinase inhibitors and monoclonal antibodies in oncology: Clinical implications. Nat. Rev. Clin. Oncol. 2016, 13, 209-227. [CrossRef] [PubMed]

5. Weinstein, I.B. Cancer. Addiction to oncogenes-The Achilles heal of cancer. Science 2002, $297,63-64$. [CrossRef] [PubMed]

6. Garraway, L.A.; Sellers, W.R. Lineage dependency and lineage-survival oncogenes in human cancer. Nat. Rev. Cancer 2006, 6, 593-602. [CrossRef] [PubMed]

7. Sharma, S.V.; Settleman, J. Oncogene addiction: Setting the stage for molecularly targeted cancer therapy. Genes Dev. 2007, 21, 3214-3231. [CrossRef] [PubMed]

8. Wagle, N.; Emery, C.; Berger, M.F.; Davis, M.J.; Sawyer, A.; Pochanard, P.; Kehoe, S.M.; Johannessen, C.M.; Macconaill, L.E.; Hahn, W.C.; et al. Dissecting therapeutic resistance to RAF inhibition in melanoma by tumor genomic profiling. J. Clin. Oncol. 2011, 29, 3085-3096. [CrossRef] [PubMed]

9. Camidge, D.R.; Pao, W.; Sequist, L.V. Acquired resistance to TKIs in solid tumours: Learning from lung cancer. Nat. Rev. Clin. Oncol. 2014, 11, 473-481. [CrossRef] [PubMed] 
10. Turner, N.C.; Reis-Filho, J.S. Genetic heterogeneity and cancer drug resistance. Lancet Oncol. 2012, 13, e178-e185. [CrossRef]

11. Marusyk, A.; Almendro, V.; Polyak, K. Intra-tumour heterogeneity: A looking glass for cancer? Nat. Rev. Cancer 2012, 12, 323-334. [CrossRef] [PubMed]

12. McGranahan, N.; Swanton, C. Biological and Therapeutic Impact of Intratumor Heterogeneity in Cancer Evolution. Cancer Cell 2015, 27, 15-26. [CrossRef] [PubMed]

13. Lawrence, M.S.; Stojanov, P.; Mermel, C.H.; Robinson, J.T.; Garraway, L.A.; Golub, T.R.; Meyerson, M.; Gabriel, S.B.; Lander, E.S.; Getz, G. Discovery and saturation analysis of cancer genes across 21 tumour types. Nature 2014, 505, 495-501. [CrossRef] [PubMed]

14. Aronson, S.J.; Rehm, H.L. Building the foundation for genomics in precision medicine. Nature 2015, 526, 336-342. [CrossRef] [PubMed]

15. Ashley, E.A. Towards precision medicine. Nat. Rev. Genet. 2016, 17, 507-522. [CrossRef] [PubMed]

16. Bradner, J.E.; Hnisz, D.; Young, R.A. Transcriptional Addiction in Cancer. Cell 2017, 168, 629-643. [CrossRef] [PubMed]

17. Loven, J.; Hoke, H.A.; Lin, C.Y.; Lau, A.; Orlando, D.A.; Vakoc, C.R.; Bradner, J.E.; Lee, T.I.; Young, R.A. Selective inhibition of tumor oncogenes by disruption of super-enhancers. Cell 2013, 153, 320-334. [CrossRef] [PubMed]

18. Kwiatkowski, N.; Zhang, T.; Rahl, P.B.; Abraham, B.J.; Reddy, J.; Ficarro, S.B.; Dastur, A.; Amzallag, A.; Ramaswamy, S.; Tesar, B.; et al. Targeting transcription regulation in cancer with a covalent CDK7 inhibitor. Nature 2014, 511, 616-620. [CrossRef] [PubMed]

19. Hnisz, D.; Abraham, B.J.; Lee, T.I.; Lau, A.; Saint-Andre, V.; Sigova, A.A.; Hoke, H.A.; Young, R.A. Super-enhancers in the control of cell identity and disease. Cell 2013, 155, 934-947. [CrossRef] [PubMed]

20. Whyte, W.A.; Orlando, D.A.; Hnisz, D.; Abraham, B.J.; Lin, C.Y.; Kagey, M.H.; Rahl, P.B.; Lee, T.I.; Young, R.A. Master transcription factors and mediator establish super-enhancers at key cell identity genes. Cell 2013, 153, 307-319. [CrossRef] [PubMed]

21. Sur, I.; Taipale, J. The role of enhancers in cancer. Nat. Rev. Cancer 2016, 16, 483-493. [CrossRef] [PubMed]

22. Shlyueva, D.; Stampfel, G.; Stark, A. Transcriptional enhancers: From properties to genome-wide predictions. Nat. Rev. Genet. 2014, 15, 272-286. [CrossRef] [PubMed]

23. Calo, E.; Wysocka, J. Modification of Enhancer Chromatin: What, How, and Why? Mol. Cell 2013, 49, 825-837. [CrossRef] [PubMed]

24. Bhagwat, A.S.; Lu, B.; Vakoc, C.R. Enhancer dysfunction in leukemia. Blood 2018, 131, 1795-1804. [CrossRef] [PubMed]

25. Look, A.T. Oncogenic transcription factors in the human acute leukemias. Science 1997, 278, $1059-1064$. [CrossRef] [PubMed]

26. Mansour, M.R.; Abraham, B.J.; Anders, L.; Berezovskaya, A.; Gutierrez, A.; Durbin, A.D.; Etchin, J.; Lawton, L.; Sallan, S.E.; Silverman, L.B.; et al. An oncogenic super-enhancer formed through somatic mutation of a noncoding intergenic element. Science 2014, 346, 1373-1377. [CrossRef] [PubMed]

27. Oldridge, D.A.; Wood, A.C.; Weichert-Leahey, N.; Crimmins, I.; Sussman, R.; Winter, C.; McDaniel, L.D.; Diamond, M.; Hart, L.S.; Zhu, S.; et al. Genetic predisposition to neuroblastoma mediated by a LMO1 super-enhancer polymorphism. Nature 2015, 528, 418-421. [CrossRef] [PubMed]

28. Li, Z.; Abraham, B.J.; Berezovskaya, A.; Farah, N.; Liu, Y.; Leon, T.; Fielding, A.; Tan, S.H.; Sanda, T.; Weintraub, A.S.; et al. APOBEC signature mutation generates an oncogenic enhancer that drives LMO1 expression in T-ALL. Leukemia 2017, 31, 2057-2064. [CrossRef] [PubMed]

29. Abraham, B.J.; Hnisz, D.; Weintraub, A.S.; Kwiatkowski, N.; Li, C.H.; Li, Z.; Weichert-Leahey, N.; Rahman, S.; Liu, Y.; Etchin, J.; et al. Small genomic insertions form enhancers that misregulate oncogenes. Nat. Commun. 2017, 8, 14385. [CrossRef] [PubMed]

30. Horn, S.; Figl, A.; Rachakonda, P.S.; Fischer, C.; Sucker, A.; Gast, A.; Kadel, S.; Moll, I.; Nagore, E.; Hemminki, K.; et al. TERT Promoter Mutations in Familial and Sporadic Melanoma. Science 2013, 339, 959-961. [CrossRef] [PubMed]

31. Huang, F.W.; Hodis, E.; Xu, M.J.; Kryukov, G.V.; Chin, L.; Garraway, L.A. Highly Recurrent TERT Promoter Mutations in Human Melanoma. Science 2013, 339, 957-959. [CrossRef] [PubMed] 
32. Vinagre, J.; Almeida, A.; Pópulo, H.; Batista, R.; Lyra, J.; Pinto, V.; Coelho, R.; Celestino, R.; Prazeres, H.; Lima, L.; et al. Frequency of TERT promoter mutations in human cancers. Nat. Commun. 2013, 4, 2185. [CrossRef] [PubMed]

33. Jones, P.A.; Baylin, S.B. The Epigenomics of Cancer. Cell 2007, 128, 683-692. [CrossRef] [PubMed]

34. Ehrlich, M. DNA methylation in cancer: Too much, but also too little. Oncogene 2002, 21, 5400-5413. [CrossRef] [PubMed]

35. Plass, C.; Pfister, S.M.; Lindroth, A.M.; Bogatyrova, O.; Claus, R.; Lichter, P. Mutations in regulators of the epigenome and their connections to global chromatin patterns in cancer. Nat. Rev. Genet. 2013, 14, 765-780. [CrossRef] [PubMed]

36. Sanda, T.; Lawton, L.N.; Barrasa, M.I.; Fan, Z.P.; Kohlhammer, H.; Gutierrez, A.; Ma, W.; Tatarek, J.; Ahn, Y.; Kelliher, M.A.; et al. Core transcriptional regulatory circuit controlled by the TAL1 complex in human T cell acute lymphoblastic leukemia. Cancer Cell 2012, 22, 209-221. [CrossRef] [PubMed]

37. Leong, W.Z.; Tan, S.H.; Ngoc, P.C.T.; Amanda, S.; Yam, A.W.Y.; Liau, W.S.; Gong, Z.; Lawton, L.N.; Tenen, D.G.; Sanda, T. ARID5B as a critical downstream target of the TAL1 complex that activates the oncogenic transcriptional program and promotes T-cell leukemogenesis. Genes Dev. 2017, 31, 2343-2360. [CrossRef] [PubMed]

38. Park, P.J. ChIP-seq: Advantages and challenges of a maturing technology. Nat. Rev. Genet. 2009, 10, 669-680. [CrossRef] [PubMed]

39. Kim, T.-K.; Shiekhattar, R. Architectural and Functional Commonalities between Enhancers and Promoters. Cell 2015, 162, 948-959. [CrossRef] [PubMed]

40. Affer, M.; Chesi, M.; Chen, W.G.; Keats, J.J.; Demchenko, Y.N.; Roschke, A.V.; Van Wier, S.; Fonseca, R.; Bergsagel, P.L.; Kuehl, W.M. Promiscuous MYC locus rearrangements hijack enhancers but mostly super-enhancers to dysregulate MYC expression in multiple myeloma. Leukemia 2014, 28, 1725-1735. [CrossRef] [PubMed]

41. Chapuy, B.; McKeown, M.R.; Lin, C.Y.; Monti, S.; Roemer, M.G.; Qi, J.; Rahl, P.B.; Sun, H.H.; Yeda, K.T.; Doench, J.G.; et al. Discovery and characterization of super-enhancer-associated dependencies in diffuse large B cell lymphoma. Cancer Cell 2013, 24, 777-790. [CrossRef] [PubMed]

42. Chipumuro, E.; Marco, E.; Christensen, C.L.; Kwiatkowski, N.; Zhang, T.; Hatheway, C.M.; Abraham, B.J.; Sharma, B.; Yeung, C.; Altabef, A.; et al. CDK7 inhibition suppresses super-enhancer-linked oncogenic transcription in MYCN-driven cancer. Cell 2014, 159, 1126-1139. [CrossRef] [PubMed]

43. Wong, R.W.J.; Ngoc, P.C.T.; Leong, W.Z.; Yam, A.W.Y.; Zhang, T.; Asamitsu, K.; Iida, S.; Okamoto, T.; Ueda, R.; Gray, N.S.; et al. Enhancer profiling identifies critical cancer genes and characterizes cell identity in adult T-cell leukemia. Blood 2017, 130, 2326-2338. [CrossRef] [PubMed]

44. Koehler, A.N. A complex task? Direct modulation of transcription factors with small molecules. Curr. Opin. Chem. Biol. 2010, 14, 331-340. [CrossRef] [PubMed]

45. Dang, C.V.; Reddy, E.P.; Shokat, K.M.; Soucek, L. Drugging the 'undruggable' cancer targets. Nat. Rev. Cancer 2017, 17, 502-508. [CrossRef] [PubMed]

46. Filippakopoulos, P.; Qi, J.; Picaud, S.; Shen, Y.; Smith, W.B.; Fedorov, O.; Morse, E.M.; Keates, T.; Hickman, T.T.; Felletar, I.; et al. Selective inhibition of BET bromodomains. Nature 2010, 468, 1067-1073. [CrossRef] [PubMed]

47. Yang, Z.; Yik, J.H.; Chen, R.; He, N.; Jang, M.K.; Ozato, K.; Zhou, Q. Recruitment of P-TEFb for stimulation of transcriptional elongation by the bromodomain protein Brd4. Mol. Cell 2005, 19, 535-545. [CrossRef] [PubMed]

48. Fong, C.Y.; Gilan, O.; Lam, E.Y.; Rubin, A.F.; Ftouni, S.; Tyler, D.; Stanley, K.; Sinha, D.; Yeh, P.; Morison, J.; et al. BET inhibitor resistance emerges from leukaemia stem cells. Nature 2015, 525, 538-542. [CrossRef] [PubMed]

49. Dawson, M.A.; Gudgin, E.J.; Horton, S.J.; Giotopoulos, G.; Meduri, E.; Robson, S.; Cannizzaro, E.; Osaki, H.; Wiese, M.; Putwain, S.; et al. Recurrent mutations, including NPM1c, activate a BRD4-dependent core transcriptional program in acute myeloid leukemia. Leukemia 2014, 28, 311-320. [CrossRef] [PubMed]

50. Zuber, J.; Shi, J.; Wang, E.; Rappaport, A.R.; Herrmann, H.; Sison, E.A.; Magoon, D.; Qi, J.; Blatt, K.; Wunderlich, M.; et al. RNAi screen identifies Brd4 as a therapeutic target in acute myeloid leukaemia. Nature 2011, 478, 524-528. [CrossRef] [PubMed] 
51. Mertz, J.A.; Conery, A.R.; Bryant, B.M.; Sandy, P.; Balasubramanian, S.; Mele, D.A.; Bergeron, L.; Sims, R.J., 3 rd. Targeting MYC dependence in cancer by inhibiting BET bromodomains. Proc. Natl. Acad. Sci. USA 2011, 108, 16669-16674. [CrossRef] [PubMed]

52. Delmore, J.E.; Issa, G.C.; Lemieux, M.E.; Rahl, P.B.; Shi, J.; Jacobs, H.M.; Kastritis, E.; Gilpatrick, T.; Paranal, R.M.; Qi, J.; et al. BET bromodomain inhibition as a therapeutic strategy to target c-Myc. Cell 2011, 146, 904-917. [CrossRef] [PubMed]

53. Harlen, K.M.; Churchman, L.S. The code and beyond: Transcription regulation by the RNA polymerase II carboxy-terminal domain. Nat. Rev. Mol. Cell Biol. 2017, 18, 263-273. [CrossRef] [PubMed]

54. Christensen, C.L.; Kwiatkowski, N.; Abraham, B.J.; Carretero, J.; Al-Shahrour, F.; Zhang, T.; Chipumuro, E.; Herter-Sprie, G.S.; Akbay, E.A.; Altabef, A.; et al. Targeting transcriptional addictions in small cell lung cancer with a covalent CDK7 inhibitor. Cancer Cell 2014, 26, 909-922. [CrossRef] [PubMed]

55. Yuan, J.; Jiang, Y.Y.; Mayakonda, A.; Huang, M.; Ding, L.W.; Lin, H.; Yu, F.; Lu, Y.; Loh, T.K.S.; Chow, M.; et al. Super-Enhancers Promote Transcriptional Dysregulation in Nasopharyngeal Carcinoma. Cancer Res. 2017, 77, 6614-6626. [CrossRef] [PubMed]

56. Hnisz, D.; Shrinivas, K.; Young, R.A.; Chakraborty, A.K.; Sharp, P.A. A Phase Separation Model for Transcriptional Control. Cell 2017, 169, 13-23. [CrossRef] [PubMed]

57. Banani, S.F.; Lee, H.O.; Hyman, A.A.; Rosen, M.K. Biomolecular condensates: Organizers of cellular biochemistry. Nat. Rev. Mol. Cell Biol. 2017, 18, 285-298. [CrossRef] [PubMed]

58. Garriga, J.; Graña, X. Cellular control of gene expression by T-type cyclin/CDK9 complexes. Gene 2004, 337, 15-23. [CrossRef] [PubMed]

59. Lam, L.T.; Pickeral, O.K.; Peng, A.C.; Rosenwald, A.; Hurt, E.M.; Giltnane, J.M.; Averett, L.M.; Zhao, H.; Davis, R.E.; Sathyamoorthy, M.; et al. Genomic-scale measurement of mRNA turnover and the mechanisms of action of the anti-cancer drug flavopiridol. Genome Biol. 2001, 2, research0041. [CrossRef] [PubMed]

60. Kelso, T.W.R.; Baumgart, K.; Eickhoff, J.; Albert, T.; Antrecht, C.; Lemcke, S.; Klebl, B.; Meisterernst, M. Cyclin-Dependent Kinase 7 Controls mRNA Synthesis by Affecting Stability of Preinitiation Complexes, Leading to Altered Gene Expression, Cell Cycle Progression, and Survival of Tumor Cells. Mol. Cell. Biol. 2014, 34, 3675-3688. [CrossRef] [PubMed]

61. Matsuoka, M.; Jeang, K.T. Human T-cell leukaemia virus type 1 (HTLV-1) infectivity and cellular transformation. Nat. Rev. Cancer 2007, 7, 270-280. [CrossRef] [PubMed]

62. Ishitsuka, K.; Tamura, K. Human T-cell leukaemia virus type I and adult T-cell leukaemia-lymphoma. Lancet Oncol. 2014, 15, e517-e526. [CrossRef]

63. Watanabe, T. Adult T-cell leukemia: Molecular basis for clonal expansion and transformation of HTLV-1-infected T cells. Blood 2017, 129, 1071-1081. [CrossRef] [PubMed]

64. Arber, D.A.; Orazi, A.; Hasserjian, R.; Thiele, J.; Borowitz, M.J.; Le Beau, M.M.; Bloomfield, C.D.; Cazzola, M.; Vardiman, J.W. The 2016 revision to the World Health Organization (WHO) classification of myeloid neoplasms and acute leukemia. Blood 2016, 127, 2391-2405. [CrossRef] [PubMed]

65. Swerdlow, S.H.; Campo, E.; Pileri, S.A.; Harris, N.L.; Stein, H.; Siebert, R.; Advani, R.; Ghielmini, M.; Salles, G.A.; Zelenetz, A.D.; et al. The 2016 revision of the World Health Organization classification of lymphoid neoplasms. Blood 2016, 127, 2375-2390. [CrossRef] [PubMed]

66. Katsuya, H.; Ishitsuka, K.; Utsunomiya, A.; Hanada, S.; Eto, T.; Moriuchi, Y.; Saburi, Y.; Miyahara, M.; Sueoka, E.; Uike, N.; et al. Treatment and survival among 1594 patients with ATL. Blood 2015, 126, 2570-2577. [CrossRef] [PubMed]

67. Takeda, S.; Maeda, M.; Morikawa, S.; Taniguchi, Y.; Yasunaga, J.; Nosaka, K.; Tanaka, Y.; Matsuoka, M. Genetic and epigenetic inactivation of tax gene in adult T-cell leukemia cells. Int. J. Cancer 2004, 109, 559-567. [CrossRef] [PubMed]

68. Satou, Y.; Yasunaga, J.; Yoshida, M.; Matsuoka, M. HTLV-I basic leucine zipper factor gene mRNA supports proliferation of adult T cell leukemia cells. Proc. Natl. Acad. Sci. USA 2006, 103, 720-725. [CrossRef] [PubMed]

69. Okamoto, T.; Ohno, Y.; Tsugane, S.; Watanabe, S.; Shimoyama, M.; Tajima, K.; Miwa, M.; Shimotohno, K. Multi-step carcinogenesis model for adult T-cell leukemia. Jpn. J. Cancer Res. 1989, 80, 191-195. [CrossRef] [PubMed] 
70. Kataoka, K.; Nagata, Y.; Kitanaka, A.; Shiraishi, Y.; Shimamura, T.; Yasunaga, J.; Totoki, Y.; Chiba, K.; Sato-Otsubo, A.; Nagae, G.; et al. Integrated molecular analysis of adult T cell leukemia/lymphoma. Nat. Genet. 2015, 47, 1304-1315. [CrossRef] [PubMed]

71. Sasaki, D.; Imaizumi, Y.; Hasegawa, H.; Osaka, A.; Tsukasaki, K.; Choi, Y.L.; Mano, H.; Marquez, V.E.; Hayashi, T.; Yanagihara, K.; et al. Overexpression of enhancer of zeste homolog 2 with trimethylation of lysine 27 on histone $\mathrm{H} 3$ in adult T-cell leukemia/lymphoma as a target for epigenetic therapy. Haematologica 2011, 96, 712-719. [CrossRef] [PubMed]

72. Fujikawa, D.; Nakagawa, S.; Hori, M.; Kurokawa, N.; Soejima, A.; Nakano, K.; Yamochi, T.; Nakashima, M.; Kobayashi, S.; Tanaka, Y.; et al. Polycomb-dependent epigenetic landscape in adult T-cell leukemia. Blood 2016, 127, 1790-1802. [CrossRef] [PubMed]

73. Dahmoush, L.; Hijazi, Y.; Barnes, E.; Stetler-Stevenson, M.; Abati, A. Adult T-cell leukemia/lymphoma: A cytopathologic, immunocytochemical, and flow cytometric study. Cancer 2002, 96, 110-116. [CrossRef] [PubMed]

74. Karube, K.; Ohshima, K.; Tsuchiya, T.; Yamaguchi, T.; Kawano, R.; Suzumiya, J.; Utsunomiya, A.; Harada, M.; Kikuchi, M. Expression of FoxP3, a key molecule in CD4CD25 regulatory T cells, in adult T-cell leukaemia/lymphoma cells. Br. J. Haematol. 2004, 126, 81-84. [CrossRef] [PubMed]

75. Gong, J.G.; Costanzo, A.; Yang, H.Q.; Melino, G.; Kaelin, W.G., Jr.; Levrero, M.; Wang, J.Y. The tyrosine kinase c-Abl regulates p73 in apoptotic response to cisplatin-induced DNA damage. Nature 1999, 399, 806-809. [CrossRef] [PubMed]

76. Yuan, Z.M.; Shioya, H.; Ishiko, T.; Sun, X.; Gu, J.; Huang, Y.Y.; Lu, H.; Kharbanda, S.; Weichselbaum, R.; Kufe, D. p73 is regulated by tyrosine kinase c-Abl in the apoptotic response to DNA damage. Nature 1999, 399, 814-817. [CrossRef] [PubMed]

77. Melino, G.; de Laurenzi, V.; Vousden, K.H. p73: Friend or foe in tumorigenesis. Nat. Rev. Cancer 2002, 2, 605-615. [CrossRef] [PubMed]

78. Ishida, T.; Utsunomiya, A.; Iida, S.; Inagaki, H.; Takatsuka, Y.; Kusumoto, S.; Takeuchi, G.; Shimizu, S.; Ito, M.; Komatsu, H.; et al. Clinical significance of CCR4 expression in adult T-cell leukemia/lymphoma: Its close association with skin involvement and unfavorable outcome. Clin. Cancer Res. 2003, 9, 3625-3634. [PubMed]

79. Ishida, T.; Iida, S.; Akatsuka, Y.; Ishii, T.; Miyazaki, M.; Komatsu, H.; Inagaki, H.; Okada, N.; Fujita, T.; Shitara, K.; et al. The CC chemokine receptor 4 as a novel specific molecular target for immunotherapy in adult T-Cell leukemia/lymphoma. Clin. Cancer Res. 2004, 10, 7529-7539. [CrossRef] [PubMed]

80. Ishida, T.; Ueda, R. Immunopathogenesis of lymphoma: Focus on CCR4. Cancer Sci. 2011, 102, 44-50. [CrossRef] [PubMed]

81. Ishida, T.; Joh, T.; Uike, N.; Yamamoto, K.; Utsunomiya, A.; Yoshida, S.; Saburi, Y.; Miyamoto, T.; Takemoto, S.; Suzushima, H.; et al. Defucosylated anti-CCR4 monoclonal antibody (KW-0761) for relapsed adult T-cell leukemia-lymphoma: A multicenter phase II study. J. Clin. Oncol. 2012, 30, 837-842. [CrossRef] [PubMed]

82. Lücking, U.; Scholz, A.; Lienau, P.; Siemeister, G.; Kosemund, D.; Bohlmann, R.; Briem, H.; Terebesi, I.; Meyer, K.; Prelle, K.; et al. Identification of Atuveciclib (BAY 1143572), the First Highly Selective, Clinical $\mathrm{PTEFb} / \mathrm{CDK} 9$ Inhibitor for the Treatment of Cancer. ChemMedChem 2017, 12, 1776-1793. [CrossRef] [PubMed]

83. Scholz, A.; Oellerich, T.; Hussain, A.; Lindner, S.; Luecking, U.; Walter, A.O.; Ellinghaus, P.; Valencia, R.; von Nussbaum, F.; Mumberg, D.; et al. Abstract 3022: BAY 1143572, a first-in-class, highly selective, potent and orally available inhibitor of PTEFb/CDK9 currently in Phase I, shows convincing anti-tumor activity in preclinical models of acute myeloid leukemia (AML). Cancer Res. 2016, 76, 3022. [CrossRef]

84. Narita, T.; Ishida, T.; Ito, A.; Masaki, A.; Kinoshita, S.; Suzuki, S.; Takino, H.; Yoshida, T.; Ri, M.; Kusumoto, S.; et al. Cyclin-dependent kinase 9 is a novel specific molecular target in adult T-cell leukemia/lymphoma. Blood 2017, 130, 1114-1124. [CrossRef] [PubMed]

85. Huang, B.; Yang, X.-D.; Zhou, M.-M.; Ozato, K.; Chen, L.-F. Brd4 Coactivates Transcriptional Activation of NF-кB via Specific Binding to Acetylated RelA. Mol. Cell. Biol. 2009, 29, 1375-1387. [CrossRef] [PubMed]

86. Sun, S.C.; Yamaoka, S. Activation of NF-kappaB by HTLV-I and implications for cell transformation. Oncogene 2005, 24, 5952-5964. [CrossRef] [PubMed]

87. Horie, R.; Watanabe, T.; Umezawa, K. Blocking NF-kappaB as a potential strategy to treat adult T-cell leukemia/lymphoma. Drug News Perspect. 2006, 19, 201-209. [CrossRef] [PubMed] 
88. Ho, Y.-K.; Zhi, H.; Bowlin, T.; Dorjbal, B.; Philip, S.; Zahoor, M.A.; Shih, H.M.; Semmes, O.J.; Schaefer, B.; Glover, J.N.; et al. HTLV-1 Tax Stimulates Ubiquitin E3 Ligase, Ring Finger Protein 8, to Assemble Lysine 63-Linked Polyubiquitin Chains for TAK1 and IKK Activation. PLOS Pathog. 2015, 11, e1005102. [CrossRef] [PubMed]

89. Iha, H.; Kibler, K.V.; Yedavalli, V.R.K.; Peloponese, J.-M.; Haller, K.; Miyazato, A.; Kasai, T.; Jeang, K.-T. Segregation of NF-KB activation through NEMO/IKK $\gamma$ by Tax and TNF $\alpha$ : Implications for stimulus-specific interruption of oncogenic signaling. Oncogene 2003, 22, 8912-8923. [CrossRef] [PubMed]

90. Harhaj, E.W.; Good, L.; Xiao, G.; Sun, S.C. Gene expression profiles in HTLV-I-immortalized T cells: Deregulated expression of genes involved in apoptosis regulation. Oncogene 1999, 18, 1341-1349. [CrossRef] [PubMed]

91. Kawakami, H.; Tomita, M.; Matsuda, T.; Ohta, T.; Tanaka, Y.; Fujii, M.; Hatano, M.; Tokuhisa, T.; Mori, N. Transcriptional activation of survivin through the NF-kB pathway by human T-cell leukemia virus type I tax. Int. J. Cancer 2005, 115, 967-974. [CrossRef] [PubMed]

92. Wu, X.; Qi, J.; Bradner, J.E.; Xiao, G.; Chen, L.-F. Bromodomain and Extraterminal (BET) Protein Inhibition Suppresses Human T Cell Leukemia Virus 1 (HTLV-1) Tax Protein-mediated Tumorigenesis by Inhibiting Nuclear Factor кB (NF-kB) Signaling. J. Biol. Chem. 2013, 288, 36094-36105. [CrossRef] [PubMed]

93. Gao, Y.; Zhang, T.; Terai, H.; Ficarro, S.B.; Kwiatkowski, N.; Hao, Mi.; Sharma, B.; Christensen, C.L.; Chipumuro, E.; Wong, K.-K.; et al. Overcoming Resistance to the THZ Series of Covalent Transcriptional CDK Inhibitors. Cell Chem. Biol. 2018, 25, 135-142.e5. [CrossRef] [PubMed]

94. Shu, S.; Lin, C.Y.; He, H.H.; Witwicki, R.M.; Tabassum, D.P.; Roberts, J.M.; Janiszewska, M.; Huh, S.J.; Liang, Y.; Ryan, J.; et al. Response and resistance to BET bromodomain inhibitors in triple-negative breast cancer. Nature 2016, 529, 413-417. [CrossRef] [PubMed]

(C) 2018 by the authors. Licensee MDPI, Basel, Switzerland. This article is an open access article distributed under the terms and conditions of the Creative Commons Attribution (CC BY) license (http:/ / creativecommons.org/licenses/by/4.0/). 